\title{
Does international experience count in the cross- cultural management course effectiveness?
}

\section{Crystal Han-Huei Tsay*}

Department of Human Resources and Organisational Behaviour, University of Greenwich, 30, Park Row, London SE10 9LS, UK

Email: h.tsay@greenwich.ac.uk

*Corresponding author

\section{Ru-Shiun Liou}

College of Business Administration, Texas A\&M University-Central Texas, 1001 Leadership Place, Room 318C, Kileen, TX 76548, USA

Email: r.liou@tamuct.edu

\begin{abstract}
The rapid increase in globalisation processes in many aspects of social and work life has pushed educators to develop students with crosscultural competence to work in culturally diverse settings. We extend the current understanding of the effectiveness of cross-cultural management courses by emphasising multidimensional learning outcomes. Furthermore, we investigate the influence of international experience on the effectiveness of cross-cultural management education. By studying 179 students at two universities, our results showed that students' international experience through international student status was positively associated with their cognitive cultural intelligence, and students' international experience through military affiliation was positively related to their motivational cultural intelligence and cross-cultural adjustment efficacy. We discuss ways to utilise experience for better learning and implications for management education.
\end{abstract}

Keywords: affective learning outcomes; cross-cultural management; cultural intelligence; international experience; international student; military experience.

Reference to this paper should be made as follows: Tsay, C.H-H. and Liou, R-S. (2016) 'Does international experience count in the cross-cultural management course effectiveness?', Int. J. Services and Standards, Vol. 11, No. 4, pp.339-356.

Biographical notes: Crystal Han-Huei Tsay is a Senior Lecturer in Human Resources and Organisational Behaviour at University of Greenwich. She received $\mathrm{PhD}$ in management from the George Washington University. Her current research interests include knowledge management in teams, educational gamification and cross-cultural learning and adaptation. She has published papers in Decision Support Systems and Informational Technology \& People. 
Dr Tsay also teaches Human Resource Management and Cross-cultural Management to both undergraduate and graduate students.

Ru-Shiun Liou received PhD in Management from the University of Arkansas and MBA from the University of Hawaii-Manoa with an emphasis in international business. Dr Liou's research focusses on emerging market firms' cross-border mergers and acquisitions as well as cross-cultural management. Her recent publication outlets include Journal of World Business, Thunderbird International Business Review and Cross Cultural \& Strategic Management Journal, and she has been presenting research at the Academy of Management and the Academy of International Business. Armed with several years of industrial experience working in retailing and consulting, she is passionate about applying management theories to understand real-world business scenarios and continues researching and sharing her research findings with her students. Dr Liou has taught management-related courses for several years, including a leadership, strategy, and global business environment courses at the undergraduate level as well as an international management course at the graduate level.

This paper is a revised and expanded version of a paper entitled 'Assessing Cognitive and Affective Learning Outcomes of an Introductory Global Business Course', presented at the 2016 Southwest Decision Sciences Institute's 47th annual meeting, Oklahoma City, March 9-12, 2016.

\section{Introduction}

The rapid increase in globalisation processes in many aspects of social and work life in the late 20th century led to a great number of individuals who frequently interact and work with others who have been socialised in different cultures. This situation has created an acute need to understand the role of national culture in management and organisational dynamics and has led to an urgent need for employees, managers, and organisations to become cross culturally competent. Practitioners and academics generally agree that cross-cultural competencies are necessary for today's global managers and desirable for domestic workers as well given today's diverse workforce (Caligiuri and Di Santo, 2001; Yamazaki and Kayes, 2004). Cross-cultural competencies are either a direct predictor or mediator of individual performance for those working overseas or working extensively with culturally diverse populations (Caligiuri and Di Santo, 2001; Caligiuri and Tarique, 2012). Furthermore, cross-cultural competencies benefit domestic workers, so that they can work more effectively with immigrant workers, expatriates, and customers and clients from different countries (Florkowski and Fogel, 1999).

From the management educator's perspective, cross-cultural management (CCM) courses must equip students with knowledge, competencies, and decision rules that will help them navigate the complexities and ethical dilemmas involved in managing in a global stakeholder environment (Eisenberg, Härtel and Stahl, 2013; Jayakumar, 2008). With the number and variety of CCM courses offered by academia and industry, some researchers have examined the effects of specific academic programs on students' crosscultural competence (Black and Duhon, 2006; MacNab and Worthley, 2012). In a recent special issue of Academy of Management Learning and Education, several scholars 
examined the impact of academic interventions on students' cross-cultural skills and abilities (Eisenberg et al., 2013; Erez et al., 2013; Rosenblatt, Worthley and MacNab, 2013; Taras et al., 2013). Even though educators believe learning in CCM courses is a multifaceted construct with implications for multiple learning outcomes (i.e. cognitive, skill-based, and affective outcomes) ( $\mathrm{Ng}$, Van Dyne and Ang, 2009), most research on CCM program effectiveness focusses on cognitive learning outcomes, such as subjectmatter knowledge (e.g. cognitive cultural intelligence or CQ) and cognitive strategies (e.g. global identity and metacognitive CQ).

Few empirical studies have been conducted to investigate changes in motivation and attitudes as a result of academic interventions. These changes in the learner's motivation and attitudes have been characterised as affective learning outcomes by Kraiger, Ford and Salas (1993). The most examined affective learning outcome in CCM course effectiveness is probably motivational CQ. However, other affective learning outcomes that are equally critical to cross-cultural adjustment and performance, such as efficacy, ethno-relative attitudes, and goal setting (Harrison, Chadwick and Scales, 1996; Kraiger, Ford and Salas, 1993; Osman-Gani and Rockstuhl, 2009), remain relatively little examined. In fact, research with expatriates has shown that an unsuccessful international assignment (characterised by premature return, withdrawal intention, and belowexpectation performance) is associated with maladjustment (Black, Mendenhall and Oddou, 1991), which, to a great extent, is influenced by low self-efficacy and decreased self-esteem and ethnocentric attitudes (De Saissy, 2009). It is therefore critical for researchers and educators to identify effective strategies to help current and future global workers develop and maintain positive attitudes for successful cross-cultural adjustment.

Clearly, there exists a gap in the literature, since researchers overemphasise cognitive (and skill-based) learning outcomes in lieu of affective learning outcomes. One reason, as argued by Johnson, Lenartowicz and Apud (2006), is that knowledge is more easily transmitted through intellectual-based learning (e.g. lectures) than through behaviours and attitude. Another possible explanation is that scholars have not taken into account students' prior experience in their classroom learning and therefore have believed that classroom teaching cannot influence affective learning outcomes the way cross-cultural interactions do. Researchers have argued that different experiences in terms of length, domain and frequency have impacts on a person's capacity for cross-cultural adjustment and development of CQ (MacNab and Worthley, 2012; Takeuchi et al., 2005). In a similar vein, in a review on the educational benefits of travel experiences, Stone and Petrick (2013) suggested that young adults and college students experience personal growth, an increase in life skills, and cross-cultural knowledge from independent international travel.

Therefore, in this study, we examined the international experience of students in $\mathrm{CCM}$ courses and how the quantity (i.e. length of experience living abroad) and quality of their experience (i.e. international and military status) influenced not only the cognitive learning outcomes but also affective learning outcomes. Thus, we contribute to the debate on the effects of educational interventions on students' affective-based cultural competencies. 


\section{Literature review}

\subsection{CCM learning outcomes: multidimensional}

Both classroom teaching and corporate training of $\mathrm{CCM}$ aim to equip individuals with specific knowledge, skills, abilities, and other characteristics. Over the past decades, the focus of CCM education has been shifted from helping trainees gain knowledge of crosscultural differences (i.e. value-based models) to developing their cross-cultural competencies (Eisenberg, Härtel and Stahl, 2013; Szkudlarek et al., 2013), among which $\mathrm{CQ}$ is the competency that receives the most educational and research attention (Eisenberg et al., 2013; Erez et al., 2013; Li, Mobley and Kelly, 2013; MacNab and Worthley, 2012; Ng, Van Dyne and Ang, 2009). CQ is "an individual's capability to function effectively in culturally diverse contexts" (Earley and Ang, 2003, p.59). It is a dynamic end-state result rather than an innate trait, and it encompasses four dimensions of capabilities. Metacognitive $C Q$ is the ability to acquire and understand cultural knowledge and norms and to recognise cultural assumptions and others' cultural preferences during and before cultural encounters. Cognitive $C Q$ includes general and specific knowledge of economic, legal, social, and value systems in different cultures and their subcultures. Behavioural $C Q$ refers to the ability to demonstrate culturally appropriate behaviours both verbally and non-verbally when interacting with people from different cultures. Finally, motivational $C Q$ means the confidence to learn about cultural differences and the desire to function in situations involving cultural differences $(\mathrm{Ng}$, Van Dyne and Ang, 2009). While metacognitive and cognitive CQ pertain to the cognitive strategies and knowledge aspects of cognitive learning outcomes, behavioural CQ is related to skill-based learning outcomes, and motivational CQ is associated with affective learning outcomes.

While CQ covers a good range of learning outcomes, we wanted to focus on the importance of affective outcomes in CCM education. Therefore, we included two additional affective learning outcomes: ethno-relative attitude and adjustment selfefficacy. Ethno-relative attitude pertains to the attitudinal facet of affective learning outcomes, whereas adjustment self-efficacy, like motivational CQ, is the motivational facet of affective learning outcomes (Kraiger, Ford and Salas, 1993). Ethno-relative attitude (which some scholars refer to as 'cosmopolitanism') recognises and accepts that beliefs, traditions, and behaviours vary across cultures. A high ethno-relative attitude minimises the belief that other cultural beliefs, traditions, and behaviours are wrong or inferior to one's own (i.e. ethnocentrism). Despite limited evidence of the causal relationship between ethnocentrism and task performance, the downsides of ethnocentrism to organisations are evident. Shaffer et al. (2006) found that ethnocentrism negatively predicted expatriate international adjustment and positively predicted withdrawal cognitions. Moreover, researchers have argued that host country national $(\mathrm{HCN})$ ethnocentrism is likely to create social schism between HCNs and expatriates, thereby reducing the likelihood of mutual support (Toh and Denisi, 2007). Also, ethnocentric expatriates would be more reluctant to learn from HCNs (Toh and Denisi, 2007) and be less satisfied with their work because of little interaction with HCNs (Peltokorpi and Froese, 2014).

On the other hand, self-efficacy has been identified as an important predictor of expatriate adjustment (Bhaskar-Shrinivas et al., 2005; Black, Mendenhall and Oddou, 
1991; Hechanova, Beehr and Christiansen, 2003; Shaffer, Harrison and Gilley, 1999). Bandura (1997) referred to self-efficacy as a person's sense of being able to perform a specific set of actions. In the current study, we utilised a specific type of self-efficacy, cross-cultural adjustment efficacy, to capture affective learning outcomes. Cross-cultural adjustment efficacy is defined as perceived capabilities to adjust oneself to interact with people effectively in culturally diverse settings and to determine the persistence and effort that one will apply when encountering obstacles in cross-cultural adjustment. Cross-cultural adjustment efficacy is different from motivational CQ, in that it focusses directly on cross-cultural adjustment, which involves the belief that individuals can actively use personal and social resources to fulfil environmental demands or to change environmental parameters (Ashford and Taylor, 1990).

\subsection{International experience and CCM outcomes}

International experience has been widely examined in the development of cross-cultural competencies. Early research showed that companies led by chief executive officers with international experience financially better perform (Carpenter, Sanders and Gregersen, 2001). Furthermore, global leaders have found that international assignments add value to their personal and professional development (Gregersen, Morrison and Black, 1998). In addition to the benefits of enhancing intercultural awareness and global engagement (Paige, Fry and Stallman, 2009), research also suggests that international travel experience, such as studying abroad, has impacts on students' internal attitudinal change (e.g. perspectives or worldview) (Dwyer, 2004), self-confidence (Bachner and Zeutschel, 2009; Chieffo, 2007), and dispelling of stereotypes (Freestone and Geldens, 2008). Specifically, in the literature of CQ, researchers have agreed that cultural exposure provides individuals opportunities to develop CQ, such as developing more complex mental frameworks to make realistic and accurate expectations, learn knowledge of different sociocultural, economic, and political systems and develop self-confidence, leadership self-efficacy, and a behavioural repertoire to act appropriately in different cultures (Li, Mobley and Kelly, 2013; Ng, Van Dyne and Ang, 2009).

Recent studies in cross-cultural adjustment and CCM education have tended to treat international experience as a control variable, often measured by the length of experience living/working abroad. In the current study, we argue that both the quantity and the quality of international experience influence students' susceptibility to CCM education, which may in turn influence their learning outcomes. For instance, Takeuchi et al. (2005) examined the impact of previous international experiences (in terms of tenure, frequency, and domain) on a person's cross-cultural adjustment and concluded that international experiences matter in complex and distinct ways. Their findings showed that the frequency of international travel experiences positively influenced general adjustment. Furthermore, when participants had culturally specific travel experiences, the frequency of experience positively moderated the relationship between current assignment tenure and general adjustment, but the length of experiences negatively moderated the relationship between current assignment tenure and general adjustment.

Based on the above reasoning, we believe that students with international experience have an advantage in achieving CCM learning outcomes. With a more frequent or longer period of international experience, people are likely to develop more comprehensive cognitive schemata than those with fewer or shorter prior international experiences (Stone and Petrick, 2013). The schemata can help people learn about and adjust to a 
culture better and quick. CCM courses frequently utilise experiential learning instructional methods such as field visits, case studies, simulations, interactive exercises, and role plays (Eisenberg, Härtel and Stahl, 2013). From the experiential learning perspective, CCM courses offer people with prior international experiences the opportunity to engage in relevant experience as well as develop analytical skills to frame and reflect on the experience (MacNab and Worthley, 2012). Therefore, we believe that students with prior international experience will be more receptive to concepts and have better associations or absorptive capabilities. We thus propose that international living/working experiences are positively related to outcomes of CCM education.

Hla-f: The length of international experience is positively related to students' $C C M$ learning outcomes, including (a) metacognitive $C Q$, (b) cognitive $C Q$, (c) behavioural CQ, (d) motivational CQ, (e) ethno-relative attitude, and (f) crosscultural adjustment self-efficacy.

\subsection{Quality of international experience and CCM outcomes}

International experiences matter in complex and distinct ways, as indicated by Takeuchi et al. (2005). Although studies have examined the impacts of the number and tenure of international experiences on important cross-cultural adjustment and/or learning outcomes, few scholars have studied the quality of international experience. Based on the characteristics of our sample, we examined the influence of international experience in terms of the status of international students and that of students with military affiliation.

\subsubsection{International experience through international student status}

Several studies have focussed on international students in the literature of cross-cultural adjustment. In fact, the experience of international students may partially resemble that of expatriates. Both groups live in a host country, interact with HCNs, and are expected to perform at work or in the academic environment. Similar to scholars' findings that expatriates' previous overseas experience yielded significant and positive meta-analytic estimates for international and work adjustment (Bhaskar-Shrinivas et al., 2005) and based on research on the educational benefits of travel experiences (Stone and Petrick, 2013), we believe that the experience of international study can contribute to students' CCM learning outcomes.

The experience of being an international student helps individuals use their home countries as a point of reference when understanding norms, practices, and conventions of different cultures, particularly the culture of the country they are studying in. That is, the host country provides situational cues for international students, so that they react more strongly than domestic students when understanding similarities and differences among cultures. Also, the contrasts between the home and host cultures provide further clues for international students to learn of the assumptions and preferences of others from different cultures. Their day-to-day studying abroad experience may also help them question cultural assumptions and adjust their mental models during interactions with host country students and other HCNs. Therefore, we believe that international student status will help with the development of CCM learning.

H2a-f: The international experience gained through international student status is positively related to students' CCM learning outcomes, including (a) 
metacognitive $C Q$, (b) cognitive $C Q$, (c) behavioural $C Q$, (d) motivational $C Q$,

(e) ethno-relative attitude and (f) cross-cultural adjustment self-efficacy.

\title{
2.3.2 International experience through military affiliation
}

Due to the unique setting of the studied university, a considerable portion of participants in the study gained international experience through military affiliation. The military has increasingly recognised the importance of cross-cultural competencies in the success of military operations (Cultural Awareness in the Military, 2012). Prior to deployment, soldiers are provided a basic cultural awareness program that debriefs do's and don'ts in a given culture (McFarland, 2005). While stationed overseas, these military students have a wide variety of cultural exchange experiences. Some students rarely leave the military bases and maintain minimum exposure to the foreign culture. Other students embrace the opportunity and experience the foreign culture through daily operations with HCNs, sight-seeing activities as well as building lifelong friendship with HCNs.

In the current study, we were interested in whether students' international experience gained through military affiliation influences their susceptibility to the CCM education. It is possible that students with a military background may have a biased view on crosscultural issues due to their mission-driven military operations. However, these students who take CCM courses are no longer in the military setting. In regards to the effectiveness of CCM education, we believe that their cross-cultural exposure could equip them with a better absorptive capacity to apply CCM education and reflect on their past overseas experience. Thus, the following hypothesis is offered.

\begin{abstract}
H3a-f: International experience gained through military affiliation is positively related to students' CCM learning outcomes, including (a) metacognitive CQ, (b) cognitive $C Q$, (c) behavioural $C Q$, (d) motivational $C Q$, (e) ethno-relative attitude and (f) cross-cultural adjustment self-efficacy.
\end{abstract}

\section{Methodology}

\subsection{Sample}

Students taking an undergraduate-level CCM course at two universities in UK and US were recruited to assess their learning outcomes. We utilise a convenience sampling technique to select the UK university that serves a large population of international students and the US university that consists of many military-affiliated students. The UK university is located in a large metropolitan city, and international students account for about $21 \%$ of the student body in the university. The percentage of international students in the UK university is similar to those of other universities in the city. International students come from South and South East Asia (e.g. India, Bangladesh, Pakistan, China, Nepal, Thailand, Vietnam), Middle East (e.g. UAE, Quartar), and Eastern Europe (e.g. Poland, Bulgaria, Romania). The US university is located near a military base in a southern state. Over half of its student population has a military affiliation, such as being on active duty, retired from the military, or from a military family. The military students consist of a wide range of ranks and functionality, including marines, pilots and navy. The US university is known for its diversity in ethnicity in the area. Hence, both universities are ideal for our variables of interest. 
Data were collected during three semesters of the same courses in the two universities between 2013 and 2015. Extra credit was offered in the US but not in the UK setting. Among 179 students, 51 had a military affiliation and 81 were international students; $47 \%$ were female and $53 \%$ were male. The average age of participants was 28 , and $43 \%$ of students had visited at least one foreign country for at least 6 months.

\subsection{Dependent variables}

\subsubsection{Cultural intelligence}

The 20-item inventory developed by Ang et al. (2007) was employed to measure CQ. Each item was scored on a 7-point Likert-type scale from 1 (strongly disagree) to 7 (strongly agree). In the inventory, there are four items for metacognitive CQ $(\alpha=0.81)$, six items for cognitive CQ $(\alpha=0.86)$, five items for motivational CQ $(\alpha=0.78)$, and another five for behavioural CQ $(\alpha=0.89)$. Sample items include "I am conscious of the cultural knowledge I use when interacting with people with different cultural backgrounds", "I know the rules for expressing non-verbal behaviours in other cultures", "I enjoy living in cultures that are unfamiliar to me", and "I change my non-verbal behaviour when a cross-cultural interaction requires it".

\subsubsection{Cross-cultural adjustment efficacy}

The 7-item scale $(\alpha=0.75)$ was developed by researchers with reference to scales of expatriate adjustment, such as those of Black and Stephen (1989) and Black (1988). Sample items include "If assigned to take an international assignment to a foreign country, I would be confident that I would be able to adjust to interacting with people from other countries on a day-to-day basis" and "When I encounter difficulty communicating with people who have different cultural backgrounds from mine, I avoid talking to them" (reverse score).

\subsubsection{Ethno-relative attitudes}

We used a 6 -item scale $(\alpha=0.75$ ) of ethnocentrism developed by Florkowski and Forgel (1999) and Meeusen, de Vroome and Hooghe (2013). Sample items include "I feel that much could be learned from individuals from other countries" and "It is better for a country when all citizens share the same customs and traditions" (reverse score).

\subsection{Independent variables}

\subsubsection{Length of international experience}

Students' international experience prior to the CCM course was measured by having them list the countries they had stayed in for at least 6 months and indicating the number of months spent in each country. The total length of international experience was calculated by summing the total number of months of all countries they had visited.

\subsubsection{International status}

Students reported whether they were international students $(1=$ yes; $0=$ no $)$. 


\subsubsection{Military affiliation}

Students reported whether they were retired from the military, undertook military service at the time of their study, or were from a military family $(1=$ yes; $0=$ no $)$.

\subsection{Analysis}

Multiple regression analyses were employed to test the hypotheses. All of the regression models had a variance inflation factor value of lower than 3, suggesting no concerns for multicollinearity according to a more conservative standard (O'Brien, 2007). Gender and age were used as control variables to control for individual differences in all regression models.

\section{Results}

Table 1 reports the descriptive statistics and correlations among variables. In Table 2, all control variables were entered in Step 1. Step 2 tested the main effect of international experience across different learning outcomes in Model 1 through Model 6. The results suggest that students with more international experience tended to exhibit higher metacognitive CQ, cognitive CQ, motivational CQ, and adjustment efficacy. However, for behavioural CQ and ethno-relative attitude, the students with more international experience did not have an advantage in achieving these learning outcomes. Thus, H1 was partially supported.

In Step 3, we further delineated the students' international experience based on whether they were international students or had a military background. While international students tended to exhibit better cognitive CQ, military students tended to have better motivational CQ and adjustment efficacy. Additionally, the main effect of international experience disappeared when we used international students' status and military affiliation to provide a more detailed measure of students' international experience. Therefore, only H2b, H3d, and H3f were supported.

\subsection{Reflections on military experience}

Apart from the quantitative data, we also collected qualitative data from military students as a way to better understand how the quality of international experience influenced their learning. As evident in the positive association between motivational CQ and adjustment efficacy, students' international experience through military affiliation enhanced their desire and confidence to interact with foreign country nationals. As one student's reflection on the deployment experience pointed out:

When I touched down in Iraq in 2014, everything about that place was a 'shock' to me. Yes, we had gone through extensive training on what to expect culture-wise, but no amount of PowerPoint slides can prepare you for a new culture and how you psychologically process it. I experienced all of the emotions expressed in the definition of cultural shock not just once but repeatedly throughout the 9 months I spent in Iraq. I don't feel like I necessarily overcame the culture shock of being in Iraq and working with Iraqis, but I started to become accustomed to their ways and culture. 
Table 1 Mean, standard deviation, and correlations $(n=179)$

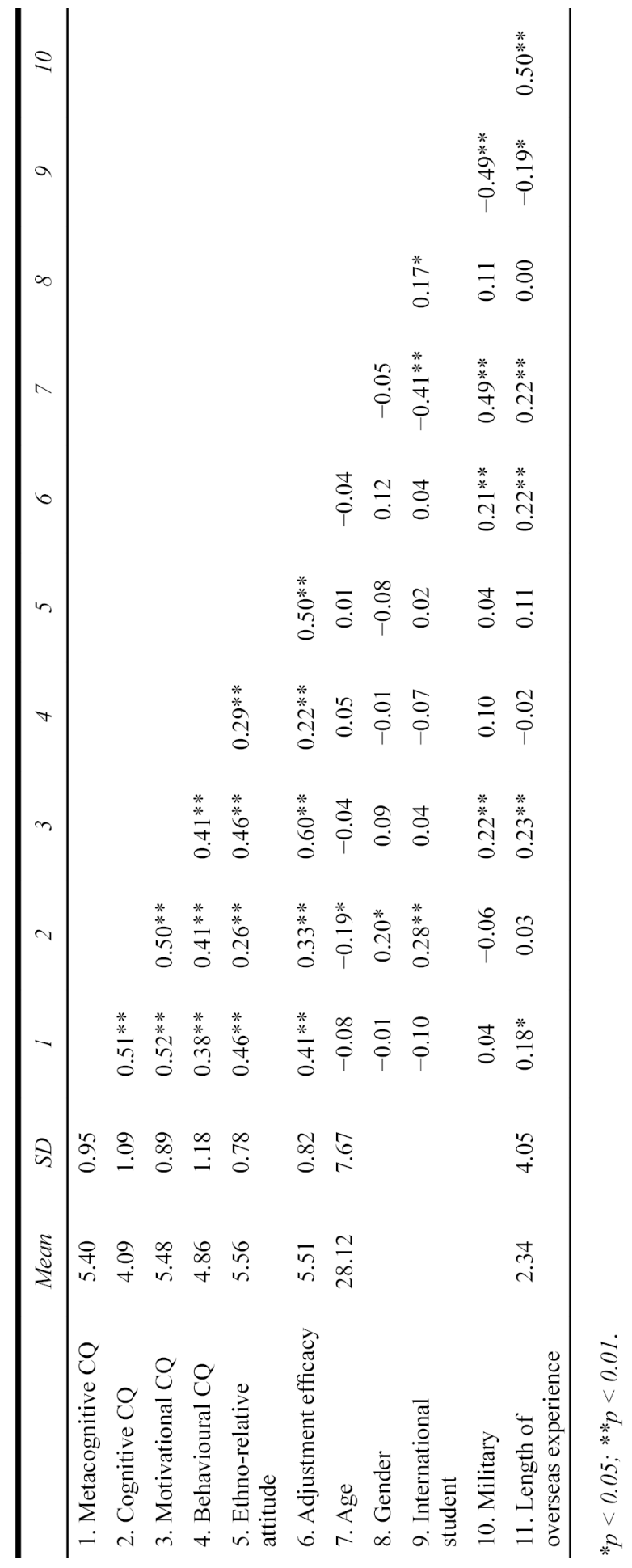


Table 2 Regression results ( $n=179)$ (see online version for colours)

\begin{tabular}{|c|c|c|c|c|c|c|}
\hline & Model 1 & Model 2 & Model 3 & Model 4 & Model 5 & Model 6 \\
\hline & $\begin{array}{c}\text { CQ1 } \\
\text { Metacognitive }\end{array}$ & $\begin{array}{c}C Q 2 \\
\text { Cognitive }\end{array}$ & $\begin{array}{c}C Q 3 \\
\text { Motivational }\end{array}$ & $\begin{array}{c}\text { CQ4 } \\
\text { Behavioural }\end{array}$ & $\begin{array}{c}\text { Ethnorelative } \\
\text { attitude }\end{array}$ & $\begin{array}{c}\text { Adjustment } \\
\text { efficacy }\end{array}$ \\
\hline \multicolumn{7}{|l|}{ Step 1} \\
\hline \multicolumn{7}{|c|}{ Control variables } \\
\hline Age & -0.074 & $-0.18^{*}$ & -0.04 & 0.036 & 0.033 & -0.03 \\
\hline Gender & -0.013 & 0.151 & 0.076 & -0.023 & -0.109 & 0.11 \\
\hline$F$ & 0.412 & $4.571^{*}$ & 0.565 & 0.142 & 1.054 & 0.979 \\
\hline Adjusted $R^{2}$ & -0.008 & 0.046 & -0.006 & -0.012 & 0.001 & 0 \\
\hline \multicolumn{7}{|l|}{ Step 2} \\
\hline \multicolumn{7}{|c|}{ Control variables } \\
\hline Age & -0.109 & -0.193 & -0.096 & 0.042 & 0.012 & -0.077 \\
\hline Gender & -0.014 & 0.151 & 0.074 & -0.023 & -0.11 & 0.11 \\
\hline \multicolumn{7}{|c|}{ Independent variables } \\
\hline $\begin{array}{l}\text { Length of } \\
\text { living abroad }\end{array}$ & $0.177^{*}$ & $0.059 *$ & $0.241 * *$ & -0.028 & 0.104 & $0.209^{*}$ \\
\hline$F$ & $1.844^{*}$ & $3.207^{*}$ & $3.217^{*}$ & 0.131 & 1.229 & $2.763^{*}$ \\
\hline Adjusted $R^{2}$ & 0.016 & 0.043 & 0.043 & -0.018 & 0.004 & 0.035 \\
\hline \multicolumn{7}{|l|}{ Step 3} \\
\hline \multicolumn{7}{|c|}{ Control variables } \\
\hline Age & -0.164 & -0.128 & -0.162 & -0.014 & 0.018 & -0.136 \\
\hline Gender & 0.011 & 0.105 & 0.021 & -0.031 & -0.124 & 0.068 \\
\hline \multicolumn{7}{|c|}{ Independent variables } \\
\hline $\begin{array}{l}\text { Length of } \\
\text { living abroad }\end{array}$ & 0.171 & 0.044 & 0.133 & -0.077 & 0.091 & 0.118 \\
\hline $\begin{array}{l}\text { International } \\
\text { student }\end{array}$ & -0.169 & $0.282 * *$ & 0.138 & -0.027 & 0.061 & 0.106 \\
\hline $\begin{array}{l}\text { Military } \\
\text { experience }\end{array}$ & -0.03 & 0.111 & $0.298 * *$ & 0.111 & 0.045 & $0.246^{*}$ \\
\hline Observations & 154 & 150 & 149 & 151 & 153 & 147 \\
\hline$F$ & 1.751 & $3.761 * *$ & $2.446^{* *}$ & 0.348 & 0.809 & $2.608 *$ \\
\hline Adjusted $R^{2}$ & 0.024 & 0.085 & 0.077 & -0.022 & -0.006 & 0.052 \\
\hline
\end{tabular}

$* p<0.05 ; * * p<0.01$.

Note: Unstandardised coefficients are reported for tested variables. 
Another student expressed that despite the hostile environment and culture shock, military personnel could develop coping strategies to further develop cultural competence.

When I went to South Korea as 18 years old, the first thing I noticed was the Patriot Missile Systems that were lined up along the runway when the plane landed in Osan Air Force Base. I knew that North Korea and South Korea had a war about 50 years before I went to South Korea, but I did not realise that tensions were still that high. That was just the beginning of my year in South Korea. My job was being a tank driver. I was driving my tank on the Korean highway and I saw a Korean police officer with a submachine gun directing traffic. I never seen a police officer so heavily armed. The last thing that freaked me out was when I was driving my tank through a rock drop. The South Korean roads that are cut through a mountain are rigged with $C-4$ explosives. They are rigged with explosives just in case North Korea decided to invade. The rock drops would explode and block the road so that the North Koreans could not pass. I tried to experience as much of the Korean culture as I could. That seemed to help. It got me used to being in the presence of the heavily armed police officers. They started to blend in with the background once I got used to the environment. Pretty soon I did not notice them at all.

Even as a military spouse, one student could reflect on the experience of living abroad and develop a sense of confidence in handling cultural differences.

\begin{abstract}
In 1985, my husband was stationed in Europe while serving his duty in the USA Air Force. We were newly married and young with a small child as well. I bought several books before we left San Antonio and tried to prepare myself for our adventure. We arrived in England in May and served 3 years. I am from San Antonio so my immediate reaction to the gloomy England weather was dismal. We had a lot of adjusting to do in the following months. We had to learn the currency exchange rate, we needed to buy adapters for all of our appliances to work, and we had to 'slow down'. We quickly learned to spend time with other military families to gain tips and advice which would guide us through the next 3 years. Within 3 months we were living off post and mingling with Britons. England moves at much slower pace than USA. I was used to meeting every desire immediately living in San Antonio. But in England, tea breaks and a general relaxed style of doing business was common. I eventually grew to enjoy this lifestyle change and upon returning to USA I was a little overwhelmed with my home country's pace.
\end{abstract}

Indeed, based on these students' reflection on their deployment experience, it is apparent that they experienced several critical 'cultural trigger events' that exposed them to challenging assignments, hardships, and significant personal events and subsequently equipped them with a better aptitude for developing cross-cultural competence (Reichard et al., 2015).

\title{
5 Discussion and limitations
}

In the setting of international business, it is critical to understand the cultural differences in making sound, ethical decisions to be an effective leader in different cultural contexts (Essounga-Njan et al., 2013). The acute need for cross-cultural competencies in the workplace is reflected in the association to advance collegiate schools of business (AACSB) accreditation process. In its recent publication Eligibility Procedures and Accreditation Standards, the AACSB (2015) stated that "schools should foster sensitivity 
towards and greater understanding of cultural differences and global perspective. Graduates should be prepared to pursue business or management careers in a global context and students should be exposed to cultural practices different than their own". Furthermore, one of the general skills a bachelor degree graduate should have is "the ability to work effectively in diverse environments". Thus, the AACSB explicitly expects that accredited business university programs address these values and goals through programmatic elements in undergraduate and graduate business degree programs.

Our study adds values to the AACSB standards because we suggest that educators should consider student backgrounds in designing programmatic elements. Pedagogical research suggests that student backgrounds play a significant role in evaluating effectiveness of program or course design. For example, Alshare, Hammami and Lane (2015) pointed out the importance of cultural differences in determining students' intention and acceptance to use decision support systems. Similarly, Liu and O'Farrell (2013), in studying value realisation from extensible business reporting language (XBRL), a new global data standard for business financial reporting also found that national culture moderated the impact of mandatory adoption of XBRL on analyst forecast accuracy. In relation to our study, previous cross cultural adjustment research has generally supported the notion that prior international experience can enhance a person's ability to interact effectively across cultures (Black, Mendenhall and Oddou, 1991). Other researchers have further suggested that different types of international experience impact the success and failure of international assignments to different degrees (Suutari and Brewster, 2001; Takeuchi et al., 2005). The current study was conducted in a setting where the curriculum content met the AACSB expectations of curriculum content. Furthermore, the findings of the current study provide timely insights into the critical issue of how different types of international experience influence the effectiveness of CCM education.

Our research offers insights as well as opens future avenues of research in terms of understanding what kind of experience matters and what CCM instructional methods (particularly experiential learning) may be better used in the classroom. First, it is interesting that length of international experience had a non-significant effect on learning outcomes after including types of experience. Instead, experiences through the international student and military statuses explained significant variances of the outcomes. This suggests that what matters is not how long one lives abroad, but the qualities of different types of experiences. In fact, results of a meta-analytical study showed that the effect of international experience on expatriate adjustment, although significant, is close to zero (Bhaskar-Shrinivas et al., 2005). Despite the meagre effects, researchers recognised that the rather simple frequency or year-based measures of international experience limit our understanding, and the context or location and density or quality of experience are critical in demonstrating how individuals adjust. We tried to gather students' experiences of military deployment, but we did not collect experiences of international students due to time constraints. Therefore, to fully explore the impact of quality of international experience, it is suggested that qualitative interviews be conducted with students with different types of international experiences. Based on the interview results, ideally theoretical and emerging themes can be identified and be operationalised as variables in large-scale quantitative survey studies. Further, the convenient sampling of one UK university and one US university has generated great insights as we explored whether students' international experience made a difference in 
their learning outcomes. We suggest further researchers to continue this line of research by extending the sampling to a larger pool of universities.

Different types of experiences offered students in this study advantages in performing better in some CCM learning outcomes, although not all. Our results revealed that military experience was significantly associated with two affective learning outcomes, motivational CQ and cross-cultural adjustment efficacy. Students' international experience through military affiliation enhances their desire and confidence to interact with foreign country nationals. As evident by some of the participant quotes in the Results section, the density of international experiences triggers growth in cross-cultural competencies. Furthermore, international experience through international student status helps with students' cognitive CQ, but not other aspects of CQ. Consistent with the argument of Stone and Petrick (2013), international students develop more comprehensive cognitive schemata than those with fewer or shorter prior international experiences and therefore learn about cultures more quickly and better, consequently achieving higher cognitive CQ.

To explain the non-significant effects of international student status on other learning outcomes, studying in a culture that is different from one's home culture implies changes of environmental parameters, in which individual students may easily lose familiar points of reference and therefore experience cross-cultural uncertainty and anxiety (Gao and Gudykunst, 1990) or cultural shock (Oberg, 2006). When individuals experience psychological discomfort when living in a foreign culture, a process of adjustment is needed that often involves employing a series of sense-making strategies, maintaining one's self-esteem, and regaining control over the environment (Taylor, 1983). International students need to use personal and social resources to adjust to the new cultural environment (Ployhart and Bliese, 2006). However, international academic programs are usually a short-term experience (1-year graduate programs are quite common in some countries such as UK), effective functioning in a foreign culture takes time. In fact, studies have reported that 'cultural shock' and 'learning shock' are more likely among students undertaking a program from a different disciplinary background or students whose home country is very different from the host country where they are studying (De Saissy, 2009; Gabriel and Griffiths, 2008; Molinsky, 2010). These shocks may hinder students' self-confidence and esteem, and it takes time for them to recover. Also, unlike most expatriates, many international students do not have sufficient financial and network resources to help them cope with demands in the new cultural environment. Therefore, the non-significant effect of this experience on CCM learning outcomes may be influenced by time and resources. A related explanation is that, similar to the reasoning of Johnson, Lenartowicz and Apud (2006) stated earlier, cognitive learning outcomes take less time to enhance, whereas affective learning outcomes may be enhanced over a longer time and/or retrospection. Despite the practical difficulty, it may be useful to see the impacts of CCM education on affective learning outcomes in a longer time frame.

Second, our results showed that types of international experiences give students' advantages in improving on different kinds of learning outcomes. While scholars may think affective learning outcomes are best influenced by experiences, more researchers have argued that experiential learning can achieve similar outcomes, and they have started examining the influence of experiential learning (Fowler and Blohm, 2007; MacNab, 2012; Ng, Van Dyne and Ang, 2009; Szkudlarek et al., 2013). Even though affective learning outcomes may be achieved through CCM education, a question 
remains, as researchers do not fully understand what instrumental features are most effective for desirable affective learning outcomes. This point has been highlighted in a study of Hirata and Hirata (2015), where authors argued that developing teaching and learning approaches that give students more control and autonomy based on their own individual learning preferences and needs is important. By interviewing students with different types of international experiences, we may be able to achieve this goal. We thereby recommend that future researchers examine the relationship between experiential learning instructional methods and affective learning outcomes.

\section{References}

AACSB International (2005) Eligibility Procedures and Accreditation Standards for Business Accreditation, AACSB International, Tampa, FL.

Alshare, K.A., Hammami, H. and Lane, P.L. (2015) 'The determinants of intention and usage of DSS in the academic environment: a cross-cultural study', International Journal of Services and Standards, Vol. 10, No. 3, pp.116-133.

Ang, S., Van Dyne, L. Koh, C. Ng, K.Y. Templer, K.J. Tay, C. and Chandrasekar, N.A. (2007) 'Cultural intelligence: its measurement and effects on cultural judgment and decision making, cultural adaptation and task performance', Management and Organization Review, Vol. 3, No. 3, pp.335-371.

Ashford, S.J. and Taylor, M.S. (1990) 'Adaptation to work transitions: an integrative approach', Research in Personnel and Human Resources Management, Vol. 8, pp.1-39.

Bachner, D. and Zeutschel, U. (2009) 'Long-term effects of international educational youth exchange', Intercultural Education, Vol. 20, Supp. 1, pp.S45-S58.

Bandura, A. (1997) Self-Efficacy: The Exercise of Self-Control, Freeman, New York.

Bhaskar-Shrinivas, P., Harrison, D.A. Shaffer, M.A. and Luk, D.M. (2005) 'Input-based and timebased models of international adjustment: meta-analytic evidence and theoretical extensions', Academy of Management Journal, Vol. 48, No. 2, pp.257-281.

Black, H.T. and Duhon, D.L. (2006) 'Assessing the impact of business study abroad programs on cultural awareness and personal development', Journal of Education for Business, Vol. 81, No. 3, pp.140-144.

Black, J.S. (1988) 'Work role transitions: a study of American expatriate managers in Japan', Journal of International Business Studies, Vol. 19, No. 2, pp.277-294.

Black, J.S., Mendenhall, M. and Oddou, G. (1991) 'Toward a comprehensive model of international adjustment: an integration of multiple theoretical perspectives', Academy of Management Review, Vol. 16, No. 2, pp.291-317.

Black, J.S. and Stephen, G.K. (1989) 'The influence of the spouse on American expatriate adjustment and intent to stay in pacific rim overseas assignments', Journal of Management, Vol. 15, No. 4, pp.529-544.

Caligiuri, P. and Di Santo, V. (2001) 'Global competence: what is it, and can it be developed through global assignments?', Human Resource Planning, Vol. 24, No. 3, pp.27-35.

Caligiuri, P. and Tarique, I. (2012) 'Dynamic cross-cultural competencies and global leadership effectiveness', Journal of World Business, Vol. 47, No. 4, pp.612-622.

Carpenter, M.A., Sanders, W.G. and Gregersen, H.B. (2001) 'Bundling human capital with organizational context: the impact of international assignment experience on multinational firm performance and CEO pay', Academy of Management Journal, Vol. 44, No. 3, pp.493-511. 
Chieffo, L. (2007) 'The freshman factor: outcomes of short-term education abroad programs on first-year students', presented at NAFSA Conference, Minneapolis, MN. Available online at http://www.udel.edu/global/pdf/freshmen-abroad-outcomes.pdf (accessed March 1, 2012).

Cultural Awareness in the Military (2012) Occupational Outlook Quarterly, Vol. 56, No. 3, p.31.

De Saissy, C.K.M. (2009) 'Acculturation, self-efficacy and social support among Chinese immigrants in Northern Ireland', International Journal of Intercultural Relations, Vol. 33, No. 4, pp.291-300.

Dwyer, M.M. (2004) 'More is better: the impact of study abroad program duration', Frontiers, Vol. 10, No. 10, pp.151-163.

Earley, P.C. and Ang, S. (2003) Cultural Intelligence: Individual Interactions Across Cultures, Stanford University Press, Redwood City, California.

Eisenberg, J., Härtel, C.E. and Stahl, G.K. (2013) 'From the guest editors: cross-cultural management learning and education - exploring multiple aims, approaches, and impacts', Academy of Management Learning and Education, Vol. 12, No. 3, pp.323-329.

Eisenberg, J., Lee, H.J. Brück, F. Brenner, B. Claes, M.T. Mironski, J. and Bell, R. (2013) 'Can business schools make students culturally competent? Effects of cross-cultural management courses on cultural intelligence', Academy of Management Learning and Education, Vol. 12, No. 4, pp.603-621.

Erez, M., Lisak, A. Harush, R. Glikson, E. Nouri, R. and Shokef, E. (2013) 'Going global: developing management students' cultural intelligence and global identity in virtual culturally diverse teams', Academy of Management Learning and Education, Vol. 12, No. 3, pp.330-355.

Essounga-Njan, Y., Levine, H. Ding, N. and Mercier, S. (2013) 'Leadership and spirituality in business and public administration: a cross-cultural empirical study comparing the USA and France', International Journal of Services and Standards, Vol. 8, No. 4, pp.295-314.

Florkowski, G.W. and Fogel, D.S. (1999) 'Expatriate adjustment and commitment: the role of hostunit treatment', International Journal of Human Resource Management, Vol. 10, No. 5, pp.783-807.

Fowler, S. and Blohm, J. (2007) 'Experiential learning in intercultural training', in Silberman, M. (Ed.): The Handbook of Experiential Learning, Pfeiffer, San Francisco, CA, pp.341-359.

Freestone, P. and Geldens, P. (2008) "“For more than just the postcard": student exchange as a tourist experience?', Annals of Leisure Research, Vol. 11, No. 1-2, pp.41-56.

Gabriel, Y. and Griffiths, D.S. (2008) 'International learning groups: synergies and dysfunctions', Management Learning, Vol. 39, No. 5, pp.503-518.

Gao, G. and Gudykunst, W.B. (1990) 'Uncertainty, anxiety, and adaptation', International Journal of Intercultural Relations, Vol. 14, No. 3, pp.301-317.

Gregersen, H.B., Morrison, A.J. and Black, J.S. (1998) 'Developing leaders for the global frontier', MIT Sloan Management Review, Vol. 40, No. 1, pp.21-32.

Harrison, J.K., Chadwick, M. and Scales, M. (1996) 'The relationship between cross-cultural adjustment and the personality variables of self-efficacy and self-monitoring', International Journal of Intercultural Relations, Vol. 20, No. 2, pp.167-188.

Hechanova, R., Beehr, T.A. and Christiansen, N.D. (2003) 'Antecedents and consequences of employees' adjustment to overseas assignment: a meta-analytic review', Applied Psychology, Vol. 52, No. 2, pp.213-236.

Hirata, Y. and Hirata, Y. (2015) 'Japanese learners' point of view on learning management system', International Journal of Services and Standards, Vol. 10, No. 4, pp.211-224. 
Jayakumar, U. (2008) 'Can higher education meet the needs of an increasingly diverse and global society? Campus diversity and cross-cultural workforce competencies', Harvard Educational Review, Vol. 78, No. 4, pp.615-651.

Johnson, J.P., Lenartowicz, T. and Apud, S. (2006) 'Cross-cultural competence in international business: toward a definition and a model', Journal of International Business Studies, Vol. 37, No. 4, pp.525-543.

Kraiger, K., Ford, J.K. and Salas, E. (1993) 'Application of cognitive, skill-based, and affective theories of learning outcomes to new methods of training evaluation', Journal of Applied Psychology, Vol. 78, No. 2, pp.311-328.

Li, M., Mobley, W.H. and Kelly, A. (2013) 'When do global leaders learn best to develop cultural intelligence? An investigation of the moderating role of experiential learning style', Academy of Management Learning and Education, Vol. 12, No. 1, pp.32-50.

Liu, C. and O'Farrell, G. (2013) 'The impact of XBRL on forecast accuracy across nations', International Journal of Services and Standards, Vol. 8, No. 3, pp.247-263.

MacNab, B.R. (2012) 'An experiential approach to cultural intelligence education', Journal of Management Education, Vol. 36, No. 1, pp.66-94.

MacNab, B.R. and Worthley, R. (2012) 'Individual characteristics as predictors of cultural intelligence development: the relevance of self-efficacy', International Journal of Intercultural Relations, Vol. 36, No. 1, pp.62-71.

McFarland, M. (2005) 'Military cultural education', Military Review, Vol. 85, No. 2, pp.62-69.

Meeusen, C., de Vroome, T. and Hooghe, M. (2013) 'How does education have an impact on ethnocentrism? A structural equation analysis of cognitive, occupational status and network mechanisms', International Journal of Intercultural Relations, Vol. 37, No. 5, pp.507-522.

Molinsky, A. (2010) 'A situational approach for assessing and teaching acculturation', Journal of Management Education, Vol. 34, No. 5, pp.723-745.

Ng, K.Y., Van Dyne, L. and Ang, S. (2009) 'From experience to experiential learning: cultural intelligence as a learning capability for global leader development', Academy of Management Learning and Education, Vol. 8, No. 4, pp.511-526.

Oberg, K. (2006) 'Cultural shock: adjustment to new cultural environments', Curare, Vol. 29, No. 2, p.3.

O'Brien, R.M. (2007) 'A caution regarding rules of thumb for variance inflation factors', Quality and Quantity, Vol. 41, No. 5, pp.673-690.

Osman-Gani, A.M. and Rockstuhl, T. (2009) 'Cross-cultural training, expatriate self-efficacy, and adjustments to overseas assignments: an empirical investigation of managers in Asia', International Journal of Intercultural Relations, Vol. 33, No. 4, pp.277-290.

Paige, R.M., Fry, G.W. and Stallman, E.M. (2009) 'Study abroad for global engagement: the longterm impact of mobility experiences', Intercultural Education, Vol. 20, No. 1, pp.29-44.

Peltokorpi, V. and Froese, F. (2014) 'Expatriate personality and cultural fit: the moderating role of host country context on job satisfaction', International Business Review, Vol. 23, No. 1, pp.293-302.

Ployhart, R.E. and Bliese, P.D. (2006) 'Individual adaptability (I-ADAPT) theory: conceptualizing the antecedents, consequences, and measurement of individual differences in adaptability', in Burke, C.S., Pierce, L.G. and Salas, E. (Eds.): Understanding Adaptability: A prerequisite for Effective Performance Within Complex Environments, Emerald Group Publishing, Amsterdam, pp.3-39. 
Reichard, R.J., Serrano, S.A. Condren, M. Wilder, N. Dolliwet, M. and Wang, W. (2015) 'Engagement in cultural trigger events in the development of cultural competence', Academy of Management Learning and Education, Vol. 14, No. 4, pp.461-481.

Rosenblatt, V., Worthley, R. and MacNab, B. (2013) 'From contact to development in experiential cultural intelligence education: the mediating influence of expectancy disconfirmation', Academy of Management Learning and Education, Vol. 12, No. 3, pp.356-379.

Shaffer, M.A., Harrison, D.A. and Gilley, K.M. (1999) 'Dimensions, determinants, and differences in the expatriate adjustment process', Journal of International Business Studies, Vol. 30, No. 3, pp.557-581.

Shaffer, M.A., Harrison, D.A. Gregersen, H. Black, J.S. and Ferzandi, L.A. (2006) 'You can take it with you: individual differences and expatriate effectiveness', Journal of Applied Psychology, Vol. 91, No. 1, pp.109-125.

Stone, M.J. and Petrick, J.F. (2013) 'The educational benefits of travel experiences: a literature review', Journal of Travel Research, Vol. 52, No. 6, pp.731-744.

Suutari, V. and Brewster, C. (2001) 'Making their own way: international experience through selfinitiated foreign assignments', Journal of World Business, Vol. 35, No. 4, pp.417-436.

Szkudlarek, B., McNett, J. Romani, L. and Lane, H. (2013) 'The past, present, and future of crosscultural management education: the educators' perspective', Academy of Management Learning and Education, Vol. 12, No. 3, pp.477-493.

Takeuchi, R., Tesluk, P.E. Yun, S. and Lepak, D.P. (2005) 'An integrative view of international experience', Academy of Management Journal, Vol. 48, No. 1, pp.85-100.

Taras, V., Caprar, D. Rottig, D. Sarala, R. Zakaria, N. Zhao, F. Jiménez, A. Wankel, C. Lei, W.S. and Minor, M. (2013) 'A global classroom? Evaluating the effectiveness of global virtual collaboration as a teaching tool in management education', Academy of Management Learning and Education, Vol. 12, No. 3, pp.414-435.

Taylor, S.E. (1983) 'Adjustment to threatening events: a theory of cognitive adaptation', American Psychologist, Vol. 38, No. 11, pp.1161-1173.

Toh, S.M. and Denisi, A.S. (2007) 'Host country nationals as socializing agents: a social identity approach', Journal of Organizational Behavior, Vol. 28, No. 3, pp.281-301.

Yamazaki, Y. and Kayes, D.C. (2004) 'An experiential approach to cross-cultural learning: a review and integration of competencies for successful expatriate adaptation', Academy of Management Learning and Education, Vol. 3, No. 4, pp.362-379. 